Document downloaded from:

http://hdl.handle.net/10251/102502

This paper must be cited as:

Marqués-Villarroya, D.; Penaranda-Foix, FL.; García-Baños, B.; Catalá Civera, JM.;

Gutiérrez Cano, JD. (2017). Enhanced Full-Wave Circuit Analysis for Modeling of a Split Cylinder Resonator. IEEE Transactions on Microwave Theory and Techniques. 65(4):11911202. doi:10.1109/TMTT.2016.2637932

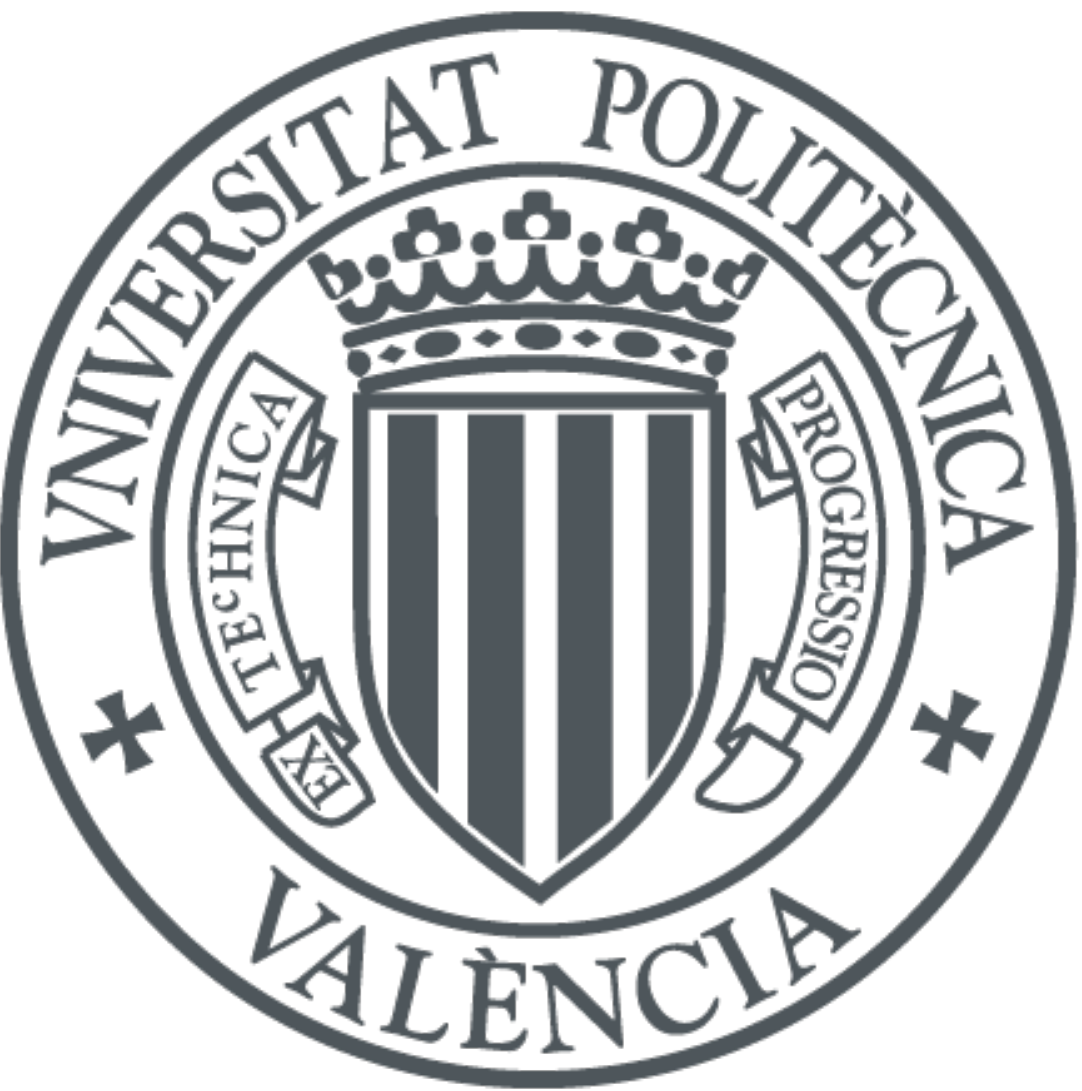

The final publication is available at

http://doi.org/10.1109/TMTT.2016.2637932

Copyright Institute of Electrical and Electronics Engineers

Additional Information 


\title{
Enhanced Full-Wave Circuit Analysis for Modeling of a Split Cylinder Resonator
}

\author{
David Marqués-Villarroya, Felipe L. Peñaranda-Foix, Senior, IEEE, Beatriz García-Baños, \\ José M. Catalá-Civera, Senior, IEEE, José D. Gutiérrez-Cano.
}

\begin{abstract}
An enhanced full wave method based on circuit analysis is presented in this paper, where the whole set of modes, $\mathrm{TE}_{\mathrm{mnp}}$ and $\mathbf{T M} \mathrm{M}_{\mathrm{mnp}}$ are taken into account. The modeling of a split cylinder resonator is done with two circuit networks of one and three ports, characterized by their generalized admittance matrix (GAM), which is computed making use of mode matching method. The improved full wave circuit method has been applied to the accurate determination of dielectric properties of materials. The proposed method has been validated through comparisons with others published models and also with measurements.
\end{abstract}

Index Terms - Electromagnetic modeling, full wave analysis, circuit analysis, mode matching method, split cylinder, dielectric measurements.

\section{INTRODUCTION}

Electromagnetic modeling has been employed to analyze microwave structures such as resonators, filters or transitions between waveguides. Over the last few decades, many methods have been developed and improved in order to obtain a more accurate solution of the problem with less computational cost. These methods include classical discretization models, like FDTD [1] or FEM [2], which are the most general and flexible methods in literature, to modal methods such as the mode-matching technique [3], which provide the most accurate solutions for particular geometries.

The discretization methods are able to model any type of shapes, however, they usually have to employ a huge mesh to accurately predict the solution, especially for eigenvalues problems, where one computes the resonant frequencies. For example, in [4], an interesting volume integral formulation is developed to model any arbitrary shape of lossy conductors filled with inhomogeneous dielectric, and about 1200

Manuscript received June, 2016.

The author Marques-Villarroya thanks to the Universitat Politècnica de València for the economic support to stay in U.S. ("Programa para la formación de personal investigador (FPI) de la UPV").

The author Peñarada-Foix thanks to the Conselleria de Educación of the Generalitat Valenciana for economic support to the stay in the U.S. (BEST/2016/012).

This paper has been financially supported by Ministerio de Economía y Competitividad (MINECO) -Spanish Government- and by European Regional Development Funds (ERDF) of European Union through the project SEDMICRON - TEC2015-70272-R (MINECO/FEDER).

Authors are with Instituto ITACA, Universitat Politècnica de València, Camino de Vera, s/n, 46022-Valencia, Spain (David Marques Villarroya, the corresponding author, phone: +34-96 387 9742; e-mail: damarvi3@itaca.upv.es). tetrahedrons are needed to discretize the structure. On the other hand, analytical methods are suitable to model some particular geometries, but they have the inconvenience of reanalyzing the whole problem from the beginning for each different structure.

In order to address this problem, a circuit method has been developed to analyze complex electromagnetic structures, based in [5]-[9], which consists of dividing the whole geometry into simpler canonicals elements or networks, which can be solved more easily [10]. This method has some advantages of the discretization and the modal technique, such as flexibility (discretization) and high accuracy (modal).

With circuit analysis, the complex permittivity of materials with several types of cavities [11]-[13] has been predicted accurately, even for the determination of the dynamic permittivity with temperature [14]. However, in these papers only modes with symmetry of revolution are taken into account, i.e., $\mathrm{TM}_{0 \mathrm{n}}$ or $\mathrm{TE}_{0 \mathrm{n}}$. This limitation narrows the frequency range of applicability, and the accuracy is also affected because possible couplings between higher order modes are not considered.

These problems can be reduced using a full-wave method. With full-wave modeling, it is possible to use higher-order modes leading to measurements at multiple frequencies. In addition, it provides more realistic simulations of electric field variations and interactions with samples. In the literature we can find several full-wave methods based on mode-matching technique or others combined with this one. For example, a dielectric loaded cavity is analyzed by [15] with a full-wave technique. The coupling between cylindrical combline resonators is analyzed by [16] making use of a full wave method. The modeling of inhomogeneous dielectric cylinders is developed by [17] with full multimodal scattering matrix. More recent publications such as [18] or [19] describe a fullwave mode-matching technique to model a cavity for liquid permittivity measurement or a split cylinder resonator respectively.

In this work, we propose a full-wave circuit method, which has been employed for modeling of a split cylinder resonator. This structure has been analyzed by many methods and techniques, some of them stand out for introducing notable improvements or innovations in the model. The most classical one is described by Janezic [3], which was improved including some higher-order modes in [20] and [21]. In [22], the resonant frequency for the measurement of dielectric constant becomes tunable because it includes the possibility of modifying the lengths of the upper or lower parts of the split cavity. In [19], as was mentioned above, it includes more 
modes in the model, providing measurements of higher-order resonant frequencies.

The objective of this paper is to extend the circuit theory developed for $\mathrm{TM}_{0 \mathrm{n}}$ and $\mathrm{TE}_{0 \mathrm{n}}$ modes to full-wave modes $\left(\mathrm{TM}_{\mathrm{mn}}\right.$ and $\mathrm{TE}_{\mathrm{mn}}$ modes) and apply the method for modeling of a split cylinder resonator. This paper is an extended version of [23], and it is expanded by including a deeper explanation about the theory of the full wave circuit method, experimental measurements, and more simulations and comparisons with other referred papers.

Section II describes the theory involved in the problem, which has been subdivided in subsections to develop the threeports (II- $A$ ) and the one-port (II- $B$ ) networks. The sizing of the matrices is also treated (II-C) as well as the connection between basic elements (II- $D$ ). In section III, we validate the model through comparison with published models (III- $A$ ) and through measurements (III- $B$ ). The convergence of the method is studied in III-C.

\section{THEORETICAL ANALYSIS}

A cross section of a split cylinder cavity is shown in Fig. 1a, while Fig. 1.b describes its circuit segmentation and the different networks used to model the resonant structure. Two types of networks can be distinguished - one with three ports (cylinder) and the other with one port on the inner side (ring). These networks are illustrated in Fig. 2. In both cases the admittance matrix is computed by making use of the mode matching method, where electromagnetic fields inside of the structure are approximated on each surface of the ports by series expansions of basis functions.

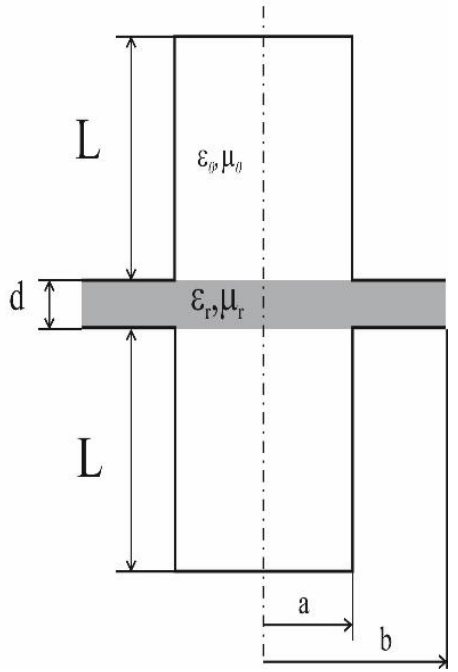

(a)

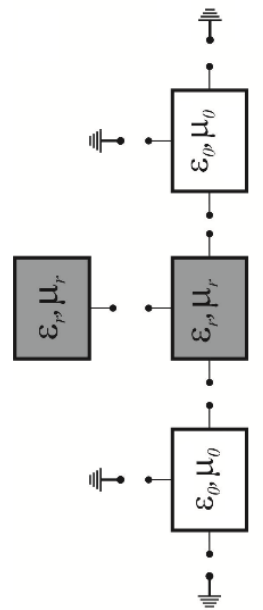

(b)
Fig 1. (a) Cross section of split cylinder cavity. (b) Circuit segmentation of the split cylinder resonator.

We take into account all the electromagnetic modes inside the structure because the proposed model consists of a full wave method, i.e., $\mathrm{TE}_{\mathrm{mn}}$ and $\mathrm{TM}_{\mathrm{mn}}$ modes (TEM modes are not possible because of the geometry). Thus, the basis function chosen must be able to approximate all these modes on the surface of each port.
The following subsections first describe the procedure to obtain the admittance matrix of each simple element by full wave circuit technique. Next is a discussion concerning the sizing of the matrices. Finally, the connection between the different networks making use of the admittance matrices obtained previously is described.

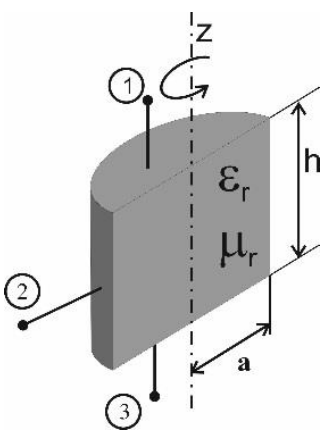

(a)

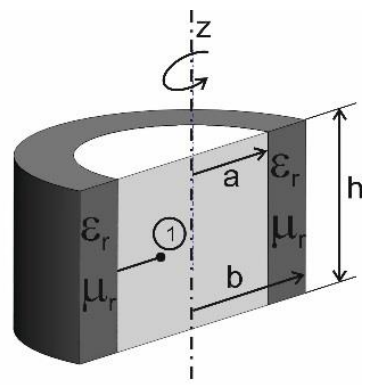

(b)
Fig 2. (a) Three-ports network. (b) One-port network

\section{A. Three Ports Network}

The three ports network consist of a cylindrical structure with three ports (see Fig. 2..a). The ports are defined as follows: port 1 at $z=h, 0 \leq r \leq a$, port 2 at $r=a, 0 \leq z \leq h$ and port 3 at $z=0,0 \leq r \leq a$. The network is filled with a generic dielectric with permittivity $\varepsilon_{r}\left(\varepsilon_{r}=\varepsilon^{\prime}-j \varepsilon^{\prime \prime}\right)$ and permeability $\mu_{r}$ $\left(\mu_{r}=\mu^{\prime}-j \mu^{\prime \prime}\right)$. The next subsections describe the procedure to obtain the admittance matrix parameters.

\section{Parameter $Y_{i l}$}

To calculate the $Y_{i l}$ parameters, electric wall conditions are imposed on ports 2 and 3 . Therefore, the following relationships are obtained as a result of applying the boundary conditions on the electromagnetic fields (see Appendix for electromagnetic fields expressions and parameters' definition):

$$
\left\{\begin{array}{c}
A_{m n}^{+}=A_{m n}^{-}(T M) \\
A_{m^{\prime} n^{\prime}}^{+}=-A_{m^{\prime} n^{\prime}}^{-}(T E) \\
k_{c m n}=\frac{\chi_{m n}}{a}(T M) \\
k_{c m^{\prime} n^{\prime}}=\frac{\chi_{m^{\prime} n^{\prime}}^{\prime}}{a}(T E)
\end{array}\right.
$$

where $\chi_{m n}$ and $\chi_{m n}^{\prime}$ are, respectively, the $n^{\text {th }}$ zero of the first kind of Bessel function and its derivative of order $m$.

The governing electric field at port $1(z=h)$ can be written as a series expansion of basis functions described in the Appendix (circular basis functions). Equating the basis functions and electromagnetic fields, the amplitudes of the fields are calculated applying orthogonal properties [24]:

$$
\begin{gathered}
\sum_{m n} E_{m n}^{T M}(r, \varphi)_{z=h} \\
+\sum_{m^{\prime} n^{\prime}} E_{m^{\prime} n^{\prime}}^{T E}(r, \varphi)_{z=h}
\end{gathered}=\begin{array}{cc}
\sum_{p q}\left(\alpha_{p q}^{S},\right. & \left.\alpha_{p q}^{c}\right) e_{p q}^{T M} \\
+\sum_{p^{\prime} q^{\prime}}\left(\beta_{p^{\prime} q^{\prime}}^{S},\right. & \left.\beta_{p^{\prime} q^{\prime}}^{c}\right) e_{p^{\prime} q^{\prime}}^{T E}
\end{array}
$$

The notation of the electric fields inside the network $\left(E_{m n}^{T M}\right.$ and $\left.E_{m^{\prime} n^{\prime}}^{T E}\right)$ and the basis functions $\left(e_{p q}^{T M}\right.$ and $\left.e_{p^{\prime} q^{\prime}}^{T E}\right)$ is 
described in the Appendix. The amplitudes of the electric fields (TE and TM) are calculated as function of electric weights of basis functions: $\alpha$ (TM electric weights) and $\beta$ (TE electric weights).

$$
\begin{array}{r}
\left(\begin{array}{c}
C_{m n}^{s} \\
C_{m n}^{c}
\end{array}\right)^{T}=\left(\begin{array}{c}
\alpha_{p q}^{s} \\
\alpha_{p q}^{c}
\end{array}\right)^{T} N_{p q}^{T M} \frac{-j \omega \varepsilon \mu}{\gamma_{m n} 2 \sin \left(\gamma_{m n} h\right)} \delta_{p m} \delta_{q n} \\
\left(\begin{array}{c}
C_{m^{\prime} n^{\prime}}^{\prime} \\
C_{m^{\prime} n^{\prime}}^{\prime c}
\end{array}\right)^{T}=\left(\begin{array}{c}
\beta_{p^{\prime} q^{\prime}}^{S} \\
\beta_{p^{\prime} q^{\prime}}^{c}
\end{array}\right)^{T} N_{p^{\prime} q^{\prime}}^{T E} \frac{-\varepsilon}{2 \sin \left(\gamma_{m^{\prime} n^{\prime}} h\right)} \delta_{p^{\prime} m^{\prime}} \delta_{q^{\prime} n^{\prime}}
\end{array}
$$

where $\delta_{m n}$ is the Kronecker delta.

It is important to remark that the orthogonalization must be done simultaneously in $r$ and $\varphi$ components in order to obtain an analytical solution of the integrals involved in the problem [25].

\section{Parameter $Y_{11}$}

The magnetic field at port $1(z=h)$ can also be written as a series expansion of basis functions (circular basis functions). The inner magnetic field and the approximation by basis function must be equal at the surface of port $1(z=h)$.

$$
\begin{gathered}
\sum_{m n} H_{m n}^{T M}(r, \varphi)_{z=h} \\
+\sum_{m^{\prime} n^{\prime}} H_{m^{\prime} n^{\prime}}^{T E}(r, \varphi)_{z=h}
\end{gathered}=\begin{gathered}
\sum_{u v}\left(c_{u v}^{S}, c_{u v}^{c}\right) h_{u v}^{T M} \\
+\sum_{u^{\prime} v^{\prime}}\left(d_{u^{\prime} v^{\prime}}^{s}, d_{u^{\prime} v^{\prime}}^{c}\right) h_{u^{\prime} v^{\prime}}^{T E}
\end{gathered}
$$

Applying the orthogonal properties of the basis functions, the parameter $Y_{11}$ is obtained as the relationship between magnetic ( $c$ and $d$ ) and electric weights of basis functions (the amplitudes of the fields have been substituted by their value calculated previously in (3) and (4)).

$$
\begin{gathered}
\left(\begin{array}{c}
c_{u v}^{s} \\
c_{u v}^{c}
\end{array}\right)^{T}=\left(\begin{array}{c}
\alpha_{p q}^{s} \\
\alpha_{p q}^{c}
\end{array}\right)^{T} \frac{-j \omega \varepsilon}{\gamma_{m n} T h\left(\gamma_{m n} h\right)} \delta_{p m} \delta_{u m} \delta_{q n} \delta_{v n} \\
\left(\begin{array}{c}
d_{u^{\prime} v^{\prime}}^{s} \\
d_{u^{\prime} v^{\prime}}^{c}
\end{array}\right)^{T}=\left(\begin{array}{c}
\beta_{p^{\prime} q^{\prime}}^{s} \\
\beta_{p^{\prime} q^{\prime}}^{c}
\end{array}\right)^{T} \frac{j \gamma_{m^{\prime} n^{\prime}}}{\omega \varepsilon \mu T h\left(\gamma_{m^{\prime} n^{\prime}} h\right)} \delta_{p^{\prime} m^{\prime}} \delta_{q^{\prime} n^{\prime}} \delta_{u^{\prime} m^{\prime}} \delta_{v^{\prime} n^{\prime}}
\end{gathered}
$$

Note that in this case, $c$ are the TM magnetic weights and $d$ are the TE magnetic weights.

\section{Parameter $Y_{21}$}

In the same way as before, the magnetic fields at port 2 $(r=a)$ can also be written as a series expansion of basis functions (in this case the lateral basis functions described in Appendix). The inner magnetic field and the approximation by basis function must be equal at the surface of port $2(r=a)$.

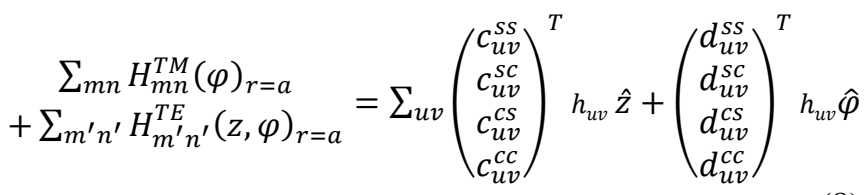

Note that the basis function on this port is complete (able to approximate any boundary condition). The orthogonalization is done in this case component by component, first for $z$ and then for $\varphi$ components of magnetic field.

Applying the orthogonal properties of basis functions, the parameter $Y_{21}$ is obtained from the relationship between magnetic and electric weights of basis functions on port 2 and 1 respectively (as before, the amplitudes of the fields have been substituted by their value calculated previously in (3) and (4)).

$$
\begin{gathered}
\left(\begin{array}{l}
c_{u v}^{s s} \\
c_{u v}^{s c} \\
c_{u v}^{c s} \\
c_{u v}^{c c}
\end{array}\right)^{T}=k^{\prime 2}{ }_{c n^{\prime}} \xi_{21} L_{1} \\
\left(\begin{array}{l}
d_{u v}^{s s} \\
d_{u v}^{s c} \\
d_{u v}^{c s} \\
d_{u v}^{c c}
\end{array}\right)^{T s}=\kappa_{21} L_{2}+\gamma_{n^{\prime}} \frac{m^{\prime}}{a} \xi_{21} L_{3}
\end{gathered}
$$

where:

$$
\begin{aligned}
& \xi_{21}=\frac{2}{h} \frac{1}{j \omega \mu} \frac{J_{m^{\prime}}\left(k^{\prime}{ }_{c n^{\prime}} a\right)}{\operatorname{sh}\left(\gamma_{m^{\prime} n^{\prime}} h\right)} \frac{N_{p^{\prime}{ }^{\prime}}^{T E} \delta_{p^{\prime} m^{\prime}} \delta_{q^{\prime} n^{\prime}} \delta_{m^{\prime} u}}{1+\operatorname{sinc}(v)} \\
& \kappa_{21}=\frac{2}{h} \frac{j \omega \varepsilon k_{c n}}{\gamma_{m n}} \frac{J_{m}^{\prime}{ }_{m}\left(k_{c n} a\right)}{\operatorname{sh}\left(\gamma_{m n} h\right)} \frac{N_{p q}^{T M} \delta_{m u} \delta_{p m} \delta_{q n}}{1+\operatorname{sinc}(v)}
\end{aligned}
$$

and the parameters $L_{i}$ are defined as follows:

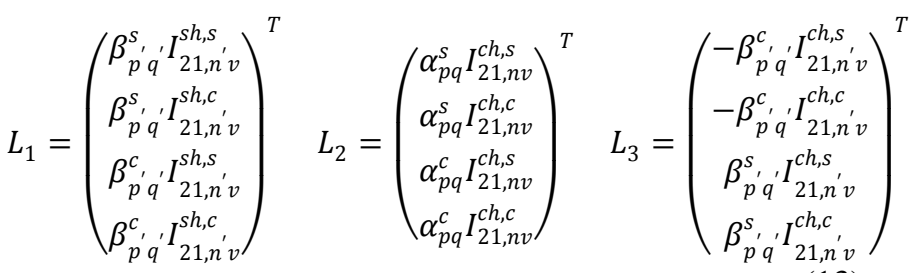

Note that in this case, $c$ are the magnetic $z$ weights and $d$ are the magnetic $\varphi$ weights of basis functions.

\section{Parameter $Y_{31}$}

The calculation of parameter $Y_{31}$ is obtained in a similar way to the $Y_{11}$ parameter, noting that port 3 is now placed at $z=0$.

\section{Parameter $Y_{i 2}$}

To calculate the $Y_{i 2}$ parameters, electric wall conditions are imposed on ports 1 and 3 . Therefore, the following relationships, as a result of applying the boundary conditions on the electromagnetic fields are obtained:

$$
\left\{\begin{array}{c}
A_{m n}^{+}=A_{m n}^{-}(T M) \\
A_{m^{\prime} n^{\prime}}^{+}=-A_{m^{\prime} n^{\prime}}^{-}(T E) \\
\gamma_{n}=\frac{j n \pi}{h}, n=0,1,2 \ldots(T M) \\
\gamma_{n^{\prime}}=\frac{j n^{\prime} \pi}{h}, n^{\prime}=1,2,3 \ldots(T E)
\end{array}\right.
$$

As we did to obtain $Y_{i l}$, the governing electric field at port 2 $(r=a)$ can be written as a series expansion of basis functions (lateral basis functions). Equating the basis function and 
electromagnetic fields, the amplitudes of the fields are calculated:

$\underset{+\sum_{m n} E_{m n}^{T M}(z, \varphi)_{r=a}}{+\sum_{m^{\prime} n^{\prime} E^{\prime}}^{T E}(\varphi)_{r=a}}=\sum_{p q}\left(\begin{array}{c}\alpha_{p q}^{s s} \\ \alpha_{p q}^{s c} \\ \alpha_{p q}^{c s} \\ \alpha_{p q}^{c c}\end{array}\right)^{T} e_{p q} \hat{z}+\left(\begin{array}{c}\beta_{p q}^{s s} \\ \beta_{p q}^{s c} \\ \beta_{p q}^{c s} \\ \beta_{p q}^{c c}\end{array}\right)^{T} e_{p q} \hat{\varphi}$

As before, the amplitudes of the electric fields (TE and TM) are expressed as function of electric weights of basis functions: $\alpha$ (electric $z$ weights) and $\beta$ (electric $\varphi$ weights).

$$
\begin{gathered}
\left(\begin{array}{c}
C_{m n}^{s} \\
C_{m n}^{c}
\end{array}\right)^{T}=\sum_{n} \xi_{i 2}\left(\begin{array}{l}
\alpha_{p q}^{s s} I_{q n}^{s, c h}+\alpha_{p q}^{s c} I_{q n}^{c, c h} \\
\alpha_{p q}^{c s} I_{q n}^{s, c h}+\alpha_{p q}^{c c} I_{q n}^{c, c h}
\end{array}\right)^{T} \\
\left(\begin{array}{c}
C^{\prime s} m^{\prime} n^{\prime} \\
C_{m^{\prime} n^{\prime}}^{\prime c}
\end{array}\right)^{T}=\sum_{n^{\prime}} \kappa_{i 2}\left(\begin{array}{c}
\Lambda_{i 2}\left(\begin{array}{c}
-\alpha_{p q}^{c s} I_{q n^{\prime}}^{s, c h}-\alpha_{p q}^{c c} I_{q n^{\prime}}^{c, c h} \\
\alpha_{p q}^{s S} I_{q n^{\prime}}^{s, c h}+\alpha_{p q}^{s c} I_{q n^{\prime}}^{c, c h}
\end{array}\right)^{T} \\
-\delta_{m^{\prime} p}\left(\begin{array}{c}
\beta_{p q}^{s s} I_{q n^{\prime}}^{s, s h}+\beta_{p q}^{s c} I_{q n^{\prime}}^{c, s h} \\
\beta_{p q}^{c s} I_{q n^{\prime}}^{s, s h}+\beta_{p q}^{c c} I_{q n^{\prime}}^{c, s h}
\end{array}\right)^{T}
\end{array}\right)
\end{gathered}
$$

where:

$$
\begin{aligned}
\xi_{i 2} & =\frac{j \omega \varepsilon \mu}{2 k_{c n^{\prime}}^{2} \cdot J_{m}\left(k_{c n} a\right) \cdot I_{n n}^{c h, c h}} \delta_{m p} \\
\kappa_{i 2} & =\frac{\varepsilon}{2 k_{c n^{\prime}}^{\prime} \cdot J^{\prime}{ }_{m^{\prime}}\left(k_{c n^{\prime}}^{\prime} a\right) I_{n^{\prime} n^{\prime}}^{s h, h}} \\
\Lambda_{i 2} & =\frac{\gamma_{n^{\prime}}}{k_{c n^{\prime}}^{2}} \frac{m^{\prime}}{a} \frac{\delta_{m m^{\prime}} \delta_{n n^{\prime}} \delta_{m^{\prime} p_{n^{\prime} n^{\prime}} I^{s h, s h}}^{I_{n^{\prime} n^{\prime}}^{c h, c h}}}{}
\end{aligned}
$$

\section{Parameter $Y_{12}$}

The inner magnetic field and the approximation by basis function must be equal at the surface of port $1(z=h)$.

$$
\begin{gathered}
\sum_{m n} H_{m n}^{T M}(r, \varphi)_{z=h} \\
+\sum_{m^{\prime} n^{\prime}} H_{m^{\prime} n^{\prime}}^{T E}(r, \varphi)_{z=h}
\end{gathered}=\begin{gathered}
\sum_{u v}\left(c_{u v}^{S}, c_{u v}^{c}\right) h_{u v}^{T M} \\
+\sum_{u^{\prime} v^{\prime}}\left(d_{u^{\prime} v^{\prime}}^{s}, d_{u^{\prime} v^{\prime}}^{c}\right) h_{u^{\prime} v^{\prime}}^{T E}
\end{gathered}
$$

Applying the orthogonal properties of basis function, the parameter $Y_{12}$ is obtained from the relationship between magnetic and electric weights of basis functions on ports 1 and 2 respectively (the amplitudes of the fields have been substituted by their value calculated previously in (16)).

$$
\begin{aligned}
& \left(\begin{array}{c}
c_{u v}^{s} \\
c_{u v}^{c}
\end{array}\right)^{T}=\sum_{n} \xi_{12} \frac{I_{12, u n v}^{T M T M}}{I_{N u v}^{T M}} \frac{\delta_{u m}}{N_{u v}^{T M}}\left(\begin{array}{c}
\alpha_{p q}^{s s} I_{q n}^{s, c h}+\alpha_{p q}^{s c} I_{q n}^{c, c h} \\
\alpha_{p q}^{c s} I_{q n}^{s, c h}+\alpha_{p q}^{c c} I_{q n}^{c, c h}
\end{array}\right)^{T} \\
& \left(\begin{array}{l}
d_{u^{\prime} v^{\prime}}^{s} \\
d_{u^{\prime} v^{\prime}}^{c}
\end{array}\right)^{T}=\left\{\begin{array}{c}
\sum_{n} \xi_{12} \frac{I_{12, u^{\prime} n v^{\prime}}^{T E T M}}{I_{N u^{\prime} v^{\prime}}^{T E}} \frac{\delta_{u^{\prime} m}}{N_{u^{\prime} v^{\prime}}^{T E}}\left(\begin{array}{c}
\alpha_{p q}^{c s} I_{q n}^{s, c h}+\alpha_{p q}^{c c} I_{q n}^{c, c h} \\
-\alpha_{p q}^{s s} I_{q n}^{s, c h}-\alpha_{p q}^{s c} I_{q n}^{c, c h}
\end{array}\right)^{T} \\
+\sum_{n^{\prime}} \kappa_{12}\left(\begin{array}{c}
\Lambda_{12}\left(\begin{array}{c}
-\alpha_{p q}^{c s} I_{q n^{\prime}}^{s, c h}-\alpha_{p q}^{c c} I_{q n^{\prime}}^{c, c h} \\
\alpha_{p q}^{s s} I_{q n^{\prime}}^{s, c h}+\alpha_{p q}^{s c} I_{q n^{\prime}}^{c, c h}
\end{array}\right)^{T} \\
-\delta_{m^{\prime} p}\left(\begin{array}{c}
\beta_{p q}^{s s} I_{q n^{\prime}}^{s, s h}+\beta_{p q}^{s c} I_{q n^{\prime}}^{c, s h} \\
\beta_{p q}^{c s} I_{q n^{\prime}}^{s, s h}+\beta_{p q}^{c c} I_{q n^{\prime}}^{c, s h}
\end{array}\right)^{T}
\end{array}\right)
\end{array}\right.
\end{aligned}
$$

where:

$$
\begin{aligned}
& \xi_{12}=\frac{j \omega \varepsilon}{k_{c n^{2} I_{n n}^{c h, c h}}^{c h}} \frac{c h\left(\gamma_{n} h\right)}{J_{m}\left(k_{c n} a\right)} \delta_{m p} \\
& \kappa_{12}=\frac{\gamma_{n^{\prime}}}{j \omega \mu k_{c n^{\prime}}^{\prime}} \frac{c h\left(\gamma_{n^{\prime}} h\right)}{J_{m^{\prime}}^{\prime}\left(k_{c n^{\prime}}^{\prime} a\right)} \frac{I_{12, u^{\prime} n^{\prime} v^{\prime}}^{T E T E}}{I_{N u^{\prime} v^{\prime}}^{T E}} \frac{\delta_{u^{\prime} m^{\prime}} \delta_{v^{\prime} n^{\prime}}}{I_{n^{\prime} n^{\prime}}^{s h, N_{u^{\prime} v^{\prime}}^{T E}}} \\
& \Lambda_{12}=\frac{m^{\prime}}{a} \frac{\gamma_{n^{\prime}{ }_{n^{\prime} n^{\prime}}^{\prime s, s h}}^{s h} \delta_{m m^{\prime}} \delta_{n n^{\prime}} \delta_{m^{\prime} p}}{k_{c n^{\prime}} I_{n^{\prime} n^{\prime}}^{c h, c h}}
\end{aligned}
$$

In this case, in the same manner that $\mathrm{Y}_{11}, c$ are the TM magnetic weights and $d$ are the TE magnetic weights.

Parameter $Y_{22}$

The inner magnetic field and the approximation by basis function must be equal at the surface of port $2(r=a)$.

$\underset{\sum_{m n} H_{m n}^{T M}(\varphi)_{r=a}}{+\sum_{m^{\prime} n^{\prime}} H_{m^{\prime} n^{\prime}}^{T E}(z, \varphi)_{r=a}}=\sum_{u v}\left(\begin{array}{c}c_{u v}^{s s} \\ c_{u v}^{s c} \\ c_{u v}^{c s} \\ c_{u v}^{c c}\end{array}\right)^{T} h_{u v} \hat{z}+\left(\begin{array}{l}d_{u v}^{s s} \\ d_{u v}^{s c} \\ d_{u v}^{c s} \\ d_{u v}^{c c}\end{array}\right)^{T} h_{u v} \hat{\varphi}$

The parameter $Y_{22}$ is obtained as the relationship between magnetic and electric weights of basis functions on port 2 .

$$
\begin{gathered}
\left(\begin{array}{l}
c_{u v}^{s s} \\
c_{u v}^{s c} \\
c_{u v}^{c s} \\
c_{u v}^{c c}
\end{array}\right)^{T}=\sum_{n^{\prime}} \xi_{22} k_{c n^{\prime}}^{\prime}\left(\kappa_{22} M_{1}-\frac{\delta_{m^{\prime} p}}{I_{n^{\prime} n^{\prime}}^{s h, s h}} M_{2}\right) \\
\left(\begin{array}{l}
d_{u v}^{s s} \\
d_{u v}^{s c} \\
d_{u v}^{c s} \\
d_{u v}^{c c}
\end{array}\right)^{T}=\sum_{n} \Lambda_{22} N_{1}-\sum_{n^{\prime}} \xi_{22} \frac{\gamma_{n^{\prime}}}{k_{c n^{\prime}}^{\prime}}\left(\kappa_{22} N_{1}+\frac{\delta_{m^{\prime} p}}{I_{n^{\prime} n^{\prime}}^{s h, s h}} N_{2}\right)
\end{gathered}
$$

where:

$$
\begin{aligned}
& \xi_{22}=\frac{-2}{h} \frac{1}{j \omega \mu} \frac{J_{m^{\prime}}\left(k^{\prime}{ }_{c n^{\prime}} a\right)}{J^{\prime}{ }_{m^{\prime}}\left(k_{c n^{\prime}}^{\prime} a\right)} \frac{\delta_{m^{\prime} u}}{(1+\operatorname{sinc}(v))} \\
& \kappa_{22}=\frac{\gamma_{n^{\prime}}}{k_{c n^{\prime}}^{2}} \frac{m^{\prime}}{a} \frac{\delta_{m m^{\prime}{ }_{n n^{\prime}} \delta_{m^{\prime} p}}}{I_{n^{\prime} n^{\prime}}^{c h}} \\
& \Lambda_{22}=\frac{-2}{h} \frac{j \omega \varepsilon}{k_{c n} I_{n n}^{c h, c h}} \frac{J_{m}^{\prime}\left(k_{c n} a\right)}{J_{m}\left(k_{c n} a\right)} \frac{\delta_{m p} \delta_{m u}}{(1+\sin c(v))}
\end{aligned}
$$

and parameters $M_{i}$ and $N_{i}$ are defined as follows:

$$
M_{1}=\left(\begin{array}{c}
-\alpha_{p q}^{c c} I_{q n^{\prime}}^{c, c h} I_{n^{\prime} v}^{s h, s} \\
-\alpha_{p q}^{c s} I_{q n^{\prime}}^{s, c h} I_{n^{\prime} v}^{s h, c} \\
\alpha_{p q}^{s c} I_{q n^{\prime}}^{c, c h} I_{n^{\prime} v}^{s h, s} \\
\alpha_{p q}^{s S} I_{q n^{\prime}}^{s, c h} I_{n^{\prime} v}^{s h, c}
\end{array}\right)^{T} \quad M_{2}=\left(\begin{array}{c}
\beta_{p q}^{s s} I_{q n^{\prime}}^{s, s h} I_{n^{\prime} v}^{s h, s} \\
\beta_{p q}^{s c} I_{q n^{\prime}}^{c, s h} I_{n^{\prime} v}^{s h, c} \\
\beta_{p q}^{c s} I_{q n^{\prime}}^{s, s h} I_{n^{\prime} v}^{s h, s} \\
\beta_{p q}^{c c} I_{q n^{\prime}}^{c, s h} I_{n^{\prime} v}^{s h, c}
\end{array}\right)^{T}
$$




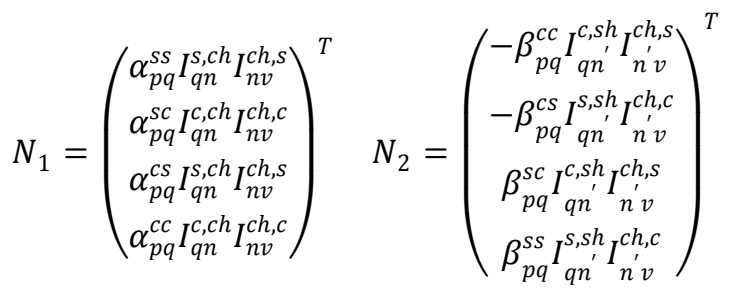

The trigonometric integrals $\left(I_{i j}^{x, y}\right)$ are defined in the Appendix. As for $\mathrm{Y}_{21}, c$ are the magnetic $z$ weights and $d$ are the magnetic $\varphi$ weights of basis functions

\section{Parameter $Y_{32}$}

The calculation of parameter $Y_{32}$ is obtained in a similar manner to the $Y_{12}$ parameter, noting that port 3 is now placed at $z=0$.

\section{B. One Port Network}

The one port network consists of a ring structure with one port as is shown in Fig.2.b. The one only port is defined at $r=a, 0 \leq z \leq h$. The network is filled with a generic dielectric with permittivity $\varepsilon_{r}\left(\varepsilon_{r}=\varepsilon^{\prime}-j \varepsilon^{\prime \prime}\right)$ and permeability $\mu_{r}$ $\left(\mu_{r}=\mu^{\prime}-j \mu^{\prime \prime}\right)$.

In this case, the boundary conditions consist of imposing electric walls at surfaces $r=b, \quad z=0$ and $z=h$, so the relationships obtained for the electromagnetic fields are:

$$
\left\{\begin{array}{c}
\Gamma_{n}=\frac{-J_{m}\left(k_{c m n} b\right)}{Y_{m}\left(k_{c m n} b\right)}(T M) \\
\Gamma_{n^{\prime}}=\frac{-J_{m^{\prime}}^{\prime}\left(k_{c m^{\prime} n^{\prime}} b\right)}{Y_{m^{\prime}}^{\prime}\left(k_{c m^{\prime} n^{\prime}} b\right)}(T E) \\
A_{m n}^{+}=A_{m n}^{-}(T M) \\
A_{m^{\prime} n^{\prime}}^{+}=-A_{m^{\prime} n^{\prime}}^{-}(T E) \\
\gamma_{n}=\frac{j n \pi}{h}, n=0,1,2 \ldots(T M) \\
\gamma_{n^{\prime}}=\frac{j n^{\prime} \pi}{h}, n^{\prime}=1,2,3 \ldots(T E)
\end{array}\right.
$$

Once the new boundary conditions are applied, the admittance matrix of this network is computed in exactly the same way as $Y_{22}$ of the three ports network.

\section{Sizing of Matrices}

The sizing of matrices is shown because it is not easily interpretable. To understand the sizing of any parameter $Y_{i j}$ is important to realize that this parameter is defined as the relationship between the magnetic weights of basis functions on port $i$ and the electric weights of basis functions on port $j$.

$$
h_{i}=Y_{i j} e_{j}
$$

In our case, on each port there are two basis functions because of the use of full wave model. For this, we have subdivided each parameter of the admittance matrices into submatrices to try to explain the sizing of them and their physical meaning.
Remember that on circular ports: $c$ are the magnetic TM weights of basis functions, $d$ are the magnetic TE weights, $\alpha$ are the electric TM weights and $\beta$ are the electric TE weights. On the lateral ports: $c$ are the magnetic $z$ weights of basis functions, $d$ are the magnetic $\varphi$ weights, $\alpha$ are the electric $z$ weights and $\beta$ are the electric $\varphi$ weights.

Then, the parameters of the admittance matrix of three-ports network are expressed as follows:

- $\quad Y_{i j}$ for $i, j:=\{1,3\}$

$$
\left(\begin{array}{l}
c_{i} \\
d_{i}
\end{array}\right)=\left[\begin{array}{ll}
Y_{i j}^{T M, T M} & Y_{i j}^{T M, T E} \\
Y_{i j}^{T E, T M} & Y_{i j}^{T E, T E}
\end{array}\right]\left(\begin{array}{c}
\alpha_{j} \\
\beta_{j}
\end{array}\right)
$$

Each submatrix represents the relationship between TM and TE modes and their possible coupling.

- $\quad Y_{22}$ (the GAM of the one-port network has the same form)

$$
\left(\begin{array}{l}
c_{2} \\
d_{2}
\end{array}\right)=\left[\begin{array}{cc}
Y_{22}^{Z, Z} & Y_{22}^{z, \varphi} \\
Y_{22}^{\varphi, z} & Y_{22}^{\varphi, \varphi}
\end{array}\right]\left(\begin{array}{l}
\alpha_{2} \\
\beta_{2}
\end{array}\right)
$$

Each submatrix represents the relationship between field components $z$ and $\varphi$ on port 2 .

- $\quad Y_{12}$ (the same for $Y_{32}$ )

$$
\left(\begin{array}{l}
c_{1} \\
d_{1}
\end{array}\right)=\left[\begin{array}{ll}
Y_{12}^{T M, Z} & Y_{12}^{T M, \varphi} \\
Y_{12}^{T E, z} & Y_{12}^{T E, \varphi}
\end{array}\right]\left(\begin{array}{c}
\alpha_{2} \\
\beta_{2}
\end{array}\right)
$$

Each submatrix represents the relationship between $\mathrm{TM}$ and TE modes in port 1 and the field components $z$ and $\varphi$ on port 2 .

- $\quad Y_{21}$ (the same for $Y_{23}$ )

$$
\left(\begin{array}{l}
c_{2} \\
d_{2}
\end{array}\right)=\left[\begin{array}{ll}
Y_{21}^{Z, T M} & Y_{21}^{Z, T E} \\
Y_{21}^{\varphi, T M} & Y_{21}^{\varphi, T E}
\end{array}\right]\left(\begin{array}{c}
\alpha_{1} \\
\beta_{1}
\end{array}\right)
$$

Each submatrix represents the relationship between the field components $z$ and $\varphi$ on port 2 and TM and TE modes on port 1.

\section{Connections of Networks}

The connections between networks are carried out making use of circuit theory [10]. One of these junctions is shown in Fig. 3, where networks A and B are joined to create network C.

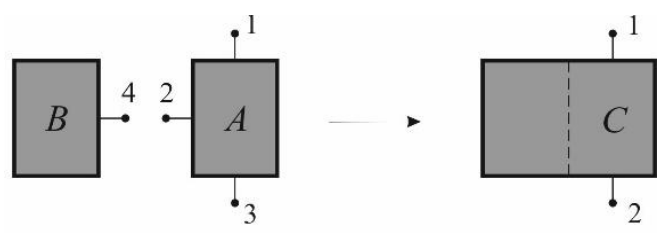

Fig 3. Connection of two networks

The admittance matrices of each simpler network (A and B) of the Fig. 3 are defined as follows:

$$
\left[\begin{array}{l}
h_{1} \\
h_{2} \\
h_{3}
\end{array}\right]=\left(\begin{array}{ccc}
Y_{11}^{A} & Y_{12}^{A} & Y_{13}^{A} \\
Y_{21}^{A} & Y_{22}^{A} & Y_{23}^{A} \\
Y_{31}^{A} & Y_{32}^{A} & Y_{33}^{A}
\end{array}\right)\left[\begin{array}{l}
e_{1} \\
e_{2} \\
e_{3}
\end{array}\right] \quad ; \quad h_{4}=Y_{44}^{B} e_{4}
$$

where $h_{i}$ and $e_{i}$ represent the magnetic and electric weights 
of basis functions on port $i$.

To join the two networks, the boundary conditions are enforced for the magnetic and electric fields between ports 2 and 4. Then, making use of the admittance matrix definition, the system of equations which provide the new admittance matrix of the junction is obtained.

The new parameters are related to the previous as follows (obtained solving the system of equations mentioned before):

$$
\left\{\begin{array}{l}
Y_{11}^{C}=Y_{11}^{A}+Y_{12}^{A}\left(Y_{44}^{B}-Y_{22}^{A}\right)^{-1} Y_{21}^{A} \\
Y_{12}^{C}=Y_{13}^{A}+Y_{12}^{A}\left(Y_{44}^{B}-Y_{22}^{A}\right)^{-1} Y_{23}^{A} \\
Y_{21}^{C}=Y_{31}^{A}+Y_{32}^{A}\left(Y_{44}^{B}-Y_{22}^{A}\right)^{-1} Y_{21}^{A} \\
Y_{22}^{C}=Y_{33}^{A}+Y_{32}^{A}\left(Y_{44}^{B}-Y_{22}^{A}\right)^{-1} Y_{23}^{A}
\end{array}\right.
$$

Applying this procedure recursively for joining all the ports of the networks, the whole geometry of the problem is obtained, represented by an admittance matrix of one single port.

Once the different simple networks are joined together using the circuit boundary conditions, only two networks remain, as shown in Fig. 1b of [23], whose GAM are $Y_{u p}$ and $Y_{\text {down }}$ following the same names than those used in [23].

It is at this point where the resonant condition is applied to compute the complex resonant frequency, defined in (43), where $\mathrm{f}_{\mathrm{r}}$ is the resonant frequency and $\mathrm{Q}$ is the quality factor, or the complex permittivity $\left(\varepsilon_{r}=\varepsilon^{\prime}-j \varepsilon^{\prime \prime}\right)$, as shown in [11], where the procedure to use the resonant condition is described.

$$
\Omega=2 \pi f_{r}\left(1+\frac{j}{2 Q}\right)
$$

\section{MeAsuREments AND Results}

In order to validate the accuracy of the method described in the previous sections, some comparisons with data published in the literature have been carried out. Furthermore, measurements with a split cylinder resonator have been also performed. Finally, a convergence study is presented, showing the number of modes necessary to get the right solution, as well as the effect of the number of modes in the computational time.

\section{A. Comparison with published data}

The first comparison is done in Table I, for symmetric nonazimuthal modes $\mathrm{TE}_{0 \mathrm{n}}$, because they were the first employed for the split cylinder resonator. The full wave circuit method is compared with the mode matching model described by [3], which is one of the first rigorous analysis of this structure. The dielectric constant is computed through the resonant frequency, which was measured by [3].

It is important to remark in this case, that the uncertainties of the geometric dimensions provided by paper [3] makes the correct comparison between both methods difficult. Nevertheless, adjusting the thickness of the sample between 3$5 \mathrm{~mm}$, as the paper specifies, we have achieved a good agreement of simulations, getting a relative difference lower than $1 \%$, validating the good behavior of the proposed method for modes $\mathrm{TE}_{0 \mathrm{n}}$.

TABLE I

COMPARISON - $\mathrm{TE}_{0 \mathrm{n}}$ MODES

$\mathrm{a}=19.09 \mathrm{~mm}, \mathrm{~b}=60 \mathrm{~mm}, \mathrm{~L}=15.22 \mathrm{~mm}, \mathrm{~d}=3$ to $5 \mathrm{~mm}$

\begin{tabular}{|c|c|c|c|}
\hline $\begin{array}{c}\mathrm{f}_{\mathrm{r}}(\mathrm{GHz}) \\
\text { Measured }\end{array}$ & $\begin{array}{c}\varepsilon_{\mathrm{r}} \\
{[3]}\end{array}$ & $\begin{array}{c}\varepsilon_{\mathrm{r}} \\
\text { (This Work) }\end{array}$ & $\Delta \varepsilon_{\mathrm{r}} / \varepsilon_{\mathrm{r}}(\%)$ \\
\hline 4.805 & 9.82 & 9.73 & 0.917 \\
\hline 4.368 & 13.57 & 13.56 & 0.074 \\
\hline 4.131 & 16.66 & 16.65 & 0.060 \\
\hline 3.866 & 20.87 & 20.81 & 0.288 \\
\hline
\end{tabular}

An improvement on the previous work was published in [26], where the mode $\mathrm{TE}_{111}$ was added in the model. With this extra mode, the analysis of split cylinder resonator with modes without symmetry of revolution was done for the first time.

TABLE II

COMPARISON $-\mathrm{TE}_{111}$ MODES

$\mathrm{a}=19.05 \mathrm{~mm}, \mathrm{~b}>27.5 \mathrm{~mm}, \mathrm{~L}=25.345 \mathrm{~mm}, \mathrm{~d}<9 \mathrm{~mm}$

\begin{tabular}{|c|c|c|c|c|}
\hline Sample & $\begin{array}{c}\mathrm{f}_{\mathrm{r}}(\mathrm{GHz}) \\
\text { Measured }\end{array}$ & $\begin{array}{c}\varepsilon_{\mathrm{r}} \\
{[26]}\end{array}$ & $\begin{array}{c}\varepsilon_{\mathrm{r}} \\
\text { (This work) }\end{array}$ & $\Delta \varepsilon_{\mathrm{r}} / \varepsilon_{\mathrm{r}}(\%)$ \\
\hline $\begin{array}{c}\text { Fused } \\
\text { Silica }\end{array}$ & 5.2128 & 3.820 & 3.816 & 0.105 \\
\hline Alumina & 4.6976 & 9.869 & 9.880 & 0.111 \\
\hline Quartz & 5.1459 & 4.424 & 4.427 & 0.068 \\
\hline
\end{tabular}

In Table II, the dataset of Table 1 from [26] is compared with our technique, and the accuracy of the full wave circuit method for the correct determination of the dielectric properties using $\mathrm{TE}_{111}$ mode is validated.

\section{TABLE III}

COMPARISON - FULL WAVE MODEL $\mathrm{a}=19.053 \mathrm{~mm}, \mathrm{~b}>>\mathrm{a}, \mathrm{L}=25.4 \mathrm{~mm}, \mathrm{~d}=0.704 \mathrm{~mm}, \varepsilon_{\mathrm{r}} \sim 4.5$

\begin{tabular}{|c|c|c|c|c|}
\hline Mode & $\begin{array}{c}\mathrm{f}_{\mathrm{r}}(\mathrm{GHz}) \\
{[19]}\end{array}$ & $\begin{array}{c}\mathrm{f}_{\mathrm{r}}(\mathrm{GHz}) \\
(\mathrm{This} \text { work })\end{array}$ & $\begin{array}{c}\left|\Delta \mathrm{f}_{\mathrm{r}}\right| \\
(\mathrm{MHz})\end{array}$ & $\Delta \mathrm{f}_{\mathrm{r}} / \mathrm{f}_{\mathrm{r}}(\%)$ \\
\hline $\mathrm{TE}_{111}$ & 5.1904 & 5.1952 & 4.78 & 0.092 \\
\hline $\mathrm{TE}_{112}$ & 7.4233 & 7.4256 & 2.34 & 0.031 \\
\hline $\mathrm{TM}_{111}$ & 9.9865 & 9.9902 & 3.69 & 0.037 \\
\hline $\mathrm{TE}_{312}$ & 12.02 & 12.0162 & 3.77 & 0.032 \\
\hline $\mathrm{TE}_{441}$ & 12.7058 & 12.7034 & 2.43 & 0.019 \\
\hline $\mathrm{TE}_{214}$ & 13.9238 & 13.9365 & 12.67 & 0.091 \\
\hline $\mathrm{TM}_{212}$ & 13.9845 & 13.9726 & 11.9 & 0.085 \\
\hline $\mathrm{TE}_{412}$ & 14.5286 & 14.5362 & 7.60 & 0.052 \\
\hline $\mathrm{TE}_{122}$ & 14.5605 & 14.5645 & 4.04 & 0.027 \\
\hline $\mathrm{TE}_{115}$ & 14.6122 & 14.6221 & 9.93 & 0.068 \\
\hline
\end{tabular}

The last comparison, Table III, is done with a full wave mode matching method developed in [19]. This is the most 
TABLE IV

MEASUREMENTS - TE $E_{0 n p}$ MODES

\begin{tabular}{|c|c|c|c|c|c|c|c|c|c|}
\hline \multirow{2}{*}{ Sample } & Mode & fr $(\mathrm{GHz})$ & $\mathrm{Q}$ & $\begin{array}{c}\varepsilon_{\mathrm{r}} \\
{[3]}\end{array}$ & $\begin{array}{c}\operatorname{tg} \delta \cdot 10^{4} \\
{[3]}\end{array}$ & $\begin{array}{c}\varepsilon_{\mathrm{r}} \\
{[13]}\end{array}$ & $\begin{array}{c}\operatorname{tg} \delta \cdot 10^{4} \\
{[13]}\end{array}$ & $\begin{array}{c}\varepsilon_{\mathrm{r}} \\
(\text { This Work) }\end{array}$ & $\begin{array}{c}\operatorname{tg} \delta \cdot 10^{4} \\
(\text { This Work })\end{array}$ \\
\hline \multirow{2}{*}{$\begin{array}{c}\text { Fused } \\
\text { Silica }\end{array}$} & $\mathrm{TE}_{011}$ & 8.671462 & 11109 & 3.84 & 1.37 & 3.84 & 1.32 & 3.85 & 1.44 \\
\cline { 2 - 10 } & $\mathrm{TE}_{013}$ & 11.92135 & 19731 & 3.83 & 1.801 & 3.84 & 1.74 & 3.85 & 1.85 \\
\hline \multirow{2}{*}{ Rexolite } & $\mathrm{TE}_{011}$ & 8.909700 & 10451 & 2.54 & 1.6 & 2.53 & 1.58 & 2.55 & 1.68 \\
\cline { 2 - 9 } & $\mathrm{TE}_{012}$ & 11.94721 & 8853 & 2.54 & 6.41 & 2.55 & 6.31 & 2.56 & 6.2 \\
\hline \multirow{2}{*}{ Glass } & $\mathrm{TE}_{011}$ & 8.831331 & 520 & 6.20 & 54.75 & 6.20 & 54.62 & 6.21 & 56.56 \\
\cline { 2 - 9 } & $\mathrm{TE}_{014}$ & 16.262571 & 1489 & 6.15 & 65.23 & 6.18 & 65.327 & 6.18 & 68.23 \\
\hline
\end{tabular}

general case, where all electromagnetic modes are taken into account. In this case, the resonant frequency of some high order modes is computed.

In the simulations, there are more TE modes than TM modes because the excitation of the cavity is designed for the propagation of only TE modes, TM modes appear because of coupling misalignment or discontinuities into the cavity.

The accuracy of the method is also validated for full wave model, as the absolute differences of resonant frequencies are only of some Megahertz, and the relative differences are less than $0.1 \%$.

\section{B. Measurements}

Once the method has been validated by simulations and comparisons with the literature, some measurements of the permittivity and the loss tangent of three different materials have been performed at NIST laboratories (in Boulder) with a split cylinder resonator, whose dimensions are: $\mathrm{a}=19.05 \mathrm{~mm}$, b>a and $\mathrm{L}=25.346 \mathrm{~mm}$. The measurement system is shown in Fig.4. The materials have been selected with different permittivity and losses in order to expand the range of validation. The thicknesses of the materials are: $\mathrm{d}_{\mathrm{FUSED}}$ SILICA $=1.953 \mathrm{~mm}, \mathrm{~d}_{\text {REXOLITE }}=2.9957 \mathrm{~mm}$ and $\mathrm{d}_{\text {GLASS }}=0.9324$ $\mathrm{mm}$. Their dielectric properties are in [27].

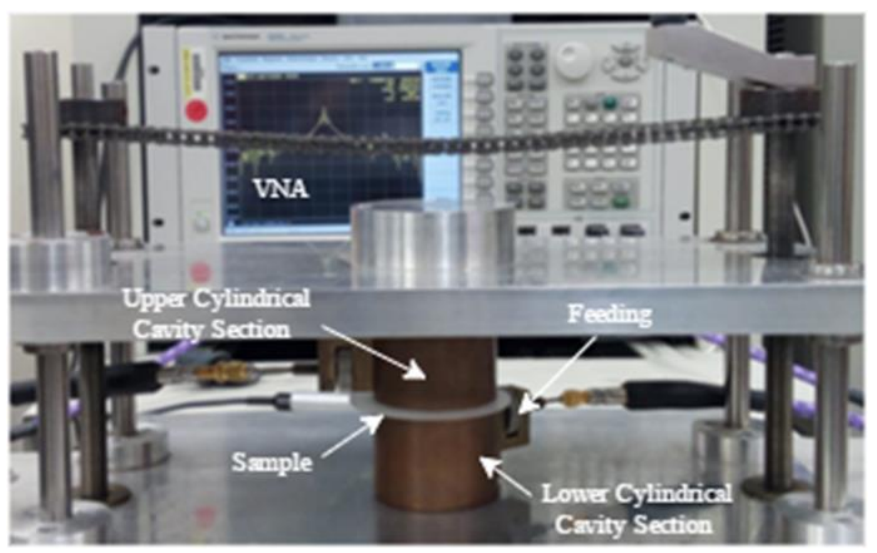

Fig 4. Split cylinder resonator and measurement set up.

In Table IV, the resonant frequency and the quality factor of some modes $\mathrm{TE}_{0 \mathrm{np}}$ have been measured, and the permittivity and the loss tangent have been computed and compared by three different methods: NIST model (mode-matching $\mathrm{TE}_{\text {Onp }}$ model [3]), circuit $\mathrm{TE}_{\text {0np }}$ model [13] and full-wave circuit model (this work). Note that the proposed method is also valid for the calculation of the complex permittivity, as the losses have also been computed in this case.

Good agreement is observed in Table IV with the results of the two referenced methods. The accuracy obtained seems to be higher for the determination of the dielectric constant.

For the correct determination of the loss tangent, the finite conductivity of the walls must be taken into account, which changes with the frequency [28]. In this work, the conductivity has been computed measuring the resonant frequency and the quality factor of each mode with the empty cavity, calculating in each case the associated conductivity for each mode.

TABLE V

MEASUREMENTS - AZIMUTHAL VARIATION MODES
\begin{tabular}{|c|c|c|c|}
\hline \multirow{2}{*}{ Sample } & Mode & $\begin{array}{c}\text { fr -Meas. } \\
(\mathrm{GHz})\end{array}$ & $\begin{array}{c}\varepsilon_{\mathrm{r}} \\
(\text { This Work })\end{array}$ \\
\hline \multirow{3}{*}{$\begin{array}{c}\text { Fused } \\
\text { Silica }\end{array}$} & $\mathrm{TE}_{111}$ & 4.872588 & 3.8045 \\
\cline { 2 - 4 } & $\mathrm{TE}_{314}$ & 13.90127 & 3.8142 \\
\cline { 2 - 4 } & $\mathrm{TE}_{123}$ & 15.86673 & 3.7675 \\
\hline \multirow{4}{*}{ Rexolite } & $\mathrm{TE}_{111}$ & 4.93875 & 2.5328 \\
\cline { 2 - 4 } & $\mathrm{TE}_{414}$ & 17.3608 & 2.5316 \\
\cline { 2 - 4 } & $\mathrm{TE}_{223}$ & 17.99497 & 2.5559 \\
\hline \multirow{3}{*}{ Glass } & $\mathrm{TE}_{111}$ & 4.952876 & 6.1429 \\
\cline { 2 - 4 } & $\mathrm{TE}_{212}$ & 7.339534 & 6.1088 \\
\cline { 2 - 4 } & $\mathrm{TE}_{113}$ & 9.09115 & 6.1501 \\
\hline
\end{tabular}

In Table $\mathrm{V}$, the applicability of the method proposed in this work for azimuthal and higher order modes is shown. The resonant frequency of modes without symmetry of revolution has been measured, and the permittivity has been computed by full wave circuit method. In particular, three modes have been measured for each material. The first resonant mode, $\mathrm{TE}_{111}$, has been performed in all the cases, and also other two higher modes, with more complex field distribution have been chosen to test the behavior of the model in these cases. The quality factor has not been measured because of the uncertainties appeared in the measurements of higher modes. Only $\mathrm{TE}_{\mathrm{mnp}}$ modes have been measured because the feeding of the cavity is designed to excite only this type of electromagnetic modes.

Note that several modes with different and varied field distribution have been used to determine the dielectric constant of the samples. In all the cases the results are 
consistent with those obtained in Table IV, validating the good behavior of the method for all type of modes, with and without symmetry of revolution, for high and low frequencies and for high and low loss materials. Note also that with full wave model we can determine the dielectric constant of the sample at more frequencies than with other simpler models. The complex permittivity could also be computed at more frequencies when the uncertainties of the measurements of the quality factor are reduced.

\section{Convergence and Computational Time}

In Fig. 5, we show how the number of modes chosen for the ports, affects the convergence and the computational time.

Three different but significant modes have been chosen to analyze the convergence of the method. The difference in computational time between the three modes is negligible, therefore, the same computed time (an average of the three similar computing times) has been presented for all of them in terms of the number of modes.

One notes in the graph that the convergence does not require many modes -8 modes in circular ports and 9 in lateral ports the results are acceptable. Introducing more modes, the results improve slowly to the ideal solution. However, the computational time required increases with the number of modes. At the end, the selection of the number of modes is a compromise between convergence and computational time. For all the tables shown in the previous sections, we have chosen between 50 to 60 modes for the circular ports and 42 to 70 in lateral ports, ensuring the convergence as well as the relative fast computation.

The computational time to find the right solution, employing the number of modes specified above, requires on average of about 45 seconds using MATLAB on an Intel Xeon E5-1607 v2 $3 \mathrm{GHz}$ PC. With the circuit method $\mathrm{TE}_{0 \mathrm{n}}$ developed in [13], the computational time is, on average about 30 seconds. Note that the computational cost is of the same order of magnitude in both cases, but obviously, the method where only modes without rotational symmetry are taken into account is faster than the method proposed in this paper. Nevertheless, it is important to emphasize that the full wave method is modeling all the electromagnetic modes inside of the cavity and their possible coupling, which is important in the accurate calculation of the dielectric properties, especially at high frequencies.

By using the analytical solution of the Bessel integrals, our full wave method is faster than others and one of the most efficient computationally. For example, in [19] all the integrals involved into the problem are computed numerically, which reduces significantly the speed and the efficiency of the method.

\section{CONCLUSION}

In this paper, an enhanced full wave method for modeling of electromagnetic structures has been presented. The method has been applied to the case of a split cylinder resonator, where the generalized admittance matrix (GAM) of two networks of one and three ports has been solved, and they

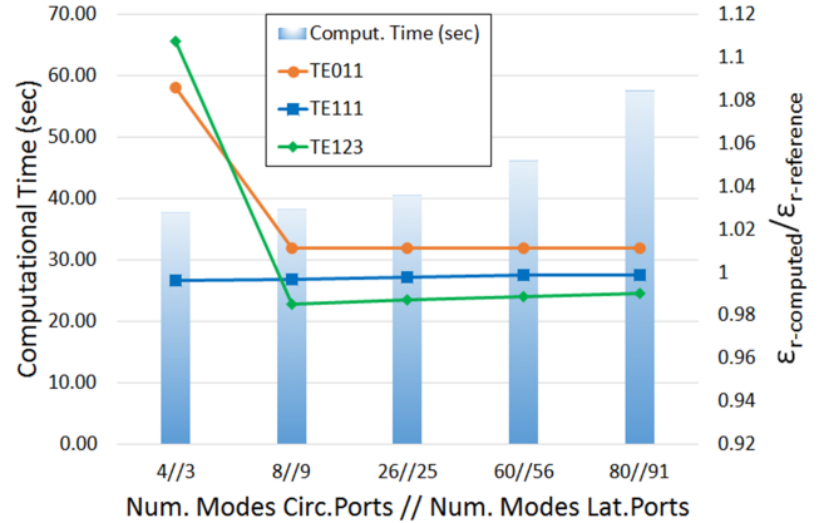

Fig 5. Convergence of the method and computational time required in terms of the number of modes used in the approach. On the abscissa axis, $\mathrm{X} / / \mathrm{Y}$ notation is employed, where $\mathrm{X}$ is the number of modes on circular ports and $\mathrm{Y}$ is the number of modes on lateral ports.

have been joined and combined to model the complete structure.

The method has been successfully validated by several simulations, comparing the results with published data, considering all the possible cases, from symmetric modes to higher order modes.

Measurements of the resonant frequencies and quality factors have been also performed, and the permittivity and loss tangent of several materials using symmetric modes have been computed and compared with two other efficient methods in literature.

The azimuthal variation modes and higher-order modes have been also employed to determinate the dielectric constant of some samples at different frequencies.

In all the cases, simulations and measurements, the good agreement of the results confirm the validity of this method, which is generally applicable to any cylindrical structure in the range of microwave frequencies. The dielectric properties of any material can be obtained, but it must be taken into account that for high permittivity and/or high loss materials, many modes are needed for the correct electromagnetic modeling because of the multiple variations of the fields inside the structure, which could reduce significantly the computational speed.

\section{APPENDIX}

In this section, we show the expressions of the electromagnetic fields, the basis functions employed along the work and the analytical integrals involved in the problem, which can be related with Bessel or trigonometric functions.

Electromagnetic fields inside the networks [29]:

$$
\boldsymbol{E}_{\mathbf{z}}=\sum_{m n} \frac{-j k_{c m n}^{2}}{\omega \varepsilon \mu} C_{m n}^{T M}\left(\begin{array}{c}
\sin (m \varphi) \\
\cos (m \varphi)
\end{array}\right) f_{m}\left(k_{c m n} r\right) A_{T M}^{+}
$$


$\boldsymbol{H}_{\boldsymbol{z}}=\sum_{m^{\prime} n^{\prime}} \frac{-j k_{c m^{\prime} n^{\prime}}^{2}}{\omega \varepsilon \mu} C_{m^{\prime} n^{\prime}}^{T E}\left(\begin{array}{c}\sin \left(m^{\prime} \varphi\right) \\ \cos \left(m^{\prime} \varphi\right)\end{array}\right) f_{m^{\prime}}\left(k_{c m^{\prime} n^{\prime}} r\right) A_{T E}^{+}$
$\boldsymbol{E}_{\boldsymbol{\rho}}=\left\{\begin{array}{l}\sum_{m n} \frac{j \gamma_{m n} k_{c m n}}{\omega \varepsilon \mu} C_{m n}^{T M}\left(\begin{array}{c}\sin (m \varphi) \\ \cos (m \varphi)\end{array}\right) f_{m}^{\prime}\left(k_{c m n} r\right) A_{T M}^{-}- \\ \sum_{m^{\prime} n^{\prime}} \frac{1}{\varepsilon} \frac{m^{\prime}}{r} C_{m^{\prime} n^{\prime}}^{T E}\left(\begin{array}{c}\cos \left(m^{\prime} \varphi\right) \\ -\sin \left(m^{\prime} \varphi\right)\end{array}\right) f_{m^{\prime}}\left(k_{c m^{\prime} n^{\prime}} r\right) A_{T E}^{+}\end{array}\right.$

$\boldsymbol{E}_{\boldsymbol{\varphi}}=\left\{\begin{array}{l}\sum_{m n} \frac{j \gamma_{m n}}{\omega \varepsilon \mu} \frac{m}{r} C_{m n}^{T M}\left(\begin{array}{c}\cos (m \varphi) \\ -\sin (m \varphi)\end{array}\right) f_{m}\left(k_{b m n} r\right) A_{T M}^{-}+ \\ \sum_{m^{\prime} n^{\prime}} \frac{k_{c m^{\prime} n^{\prime}}}{\varepsilon} C_{m^{\prime} n^{\prime}}^{T E}\left(\begin{array}{c}\sin \left(m^{\prime} \varphi\right) \\ \cos \left(m^{\prime} \varphi\right)\end{array}\right) f_{m^{\prime}}^{\prime}\left(k_{c m^{\prime} n^{\prime}} r\right) A_{T E}^{+}\end{array}\right.$

$\boldsymbol{H}_{\rho}=$

$\left\{\begin{array}{c}\sum_{m n} \frac{1}{\mu} \frac{m}{r} C_{m n}^{T M}\left(\begin{array}{c}\cos (m \varphi) \\ -\sin (m \varphi)\end{array}\right) f_{m}\left(k_{c m n} r\right) A_{T M}^{+}+ \\ \sum_{m^{\prime} n^{\prime}} \frac{j \gamma_{m^{\prime} n^{\prime}}}{\omega \varepsilon \mu} k_{c m^{\prime} n^{\prime}} C_{m^{\prime} n^{\prime}}^{T E}\left(\begin{array}{c}\sin \left(m^{\prime} \varphi\right) \\ \cos \left(m^{\prime} \varphi\right)\end{array}\right) f_{m^{\prime}}^{\prime}\left(k_{c m^{\prime} n^{\prime}} r\right) A_{T E}^{-}\end{array}\right.$

$\boldsymbol{H}_{\varphi}=$

$\left\{\begin{array}{c}\sum_{m n} \frac{-k_{c m n}}{\mu} C_{m n}^{T M}\left(\begin{array}{c}\sin (m \varphi) \\ \cos (m \varphi)\end{array}\right) f_{m}^{\prime}\left(k_{c m n} r\right) A_{T M}^{+}+ \\ \sum_{m^{\prime} n^{\prime}} \frac{j \gamma_{m^{\prime} n^{\prime}}}{\omega \varepsilon \mu} \frac{m^{\prime}}{r} C_{m^{\prime} n^{\prime}}^{T E}\left(\begin{array}{c}\cos \left(m^{\prime} \varphi\right) \\ -\sin \left(m^{\prime} \varphi\right)\end{array}\right) f_{m^{\prime}}\left(k_{c m^{\prime} n^{\prime}} r\right) A_{T E}^{-}\end{array}\right.$

where:

$$
\begin{gathered}
C_{m n}^{T M}=\left(\begin{array}{c}
C_{m n}^{s} \\
C_{m n}^{c}
\end{array}\right)^{T} \\
C_{m^{\prime} n^{\prime}}^{T E}=\left(\begin{array}{c}
C_{m^{\prime} n^{\prime}}^{s} \\
C_{m^{\prime} n^{\prime}}^{\prime c}
\end{array}\right)^{T} \\
f_{m}\left(k_{c m n} r\right)=J_{m}\left(k_{c m n} r\right)+\Gamma_{n} Y_{m}\left(k_{c m n} r\right) \\
f_{m}^{\prime}\left(k_{c m n} r\right)=J_{m}^{\prime}\left(k_{c m n} r\right)+\Gamma_{n} Y_{m}^{\prime}\left(k_{c m n} r\right) \\
A_{T M}^{+}=\left(A_{m n}^{+} e^{-\gamma_{m n} z}+A_{m n}^{-} e^{\gamma_{m n^{z}}}\right) \\
A_{T M}^{-}=\left(A_{m n}^{+} e^{-\gamma_{m n^{z}}}-A_{m n}^{-} e^{\gamma_{m n^{z}}}\right) \\
A_{T E}^{+}=\left(A_{m^{\prime} n^{\prime}}^{+} e^{-\gamma_{m^{\prime} n^{\prime}} z}+A_{m^{\prime} n^{\prime}}^{-} e^{\gamma_{m^{\prime} n^{\prime}} z}\right) \\
A_{T E}^{-}=\left(A_{m^{\prime} n^{\prime}}^{+} e^{-\gamma_{m^{\prime} n^{\prime}} z}-A_{m^{\prime} n^{\prime}}^{-} e^{\gamma_{m^{\prime} n^{\prime}} z}\right)
\end{gathered}
$$

The parameters $A_{i j}^{+}$and $A_{i j}^{-}$are the amplitudes of the progressive and regressive wave, respectively. The parameters $C_{i j}$ are the amplitudes of the trigonometric functions. When the boundary conditions are imposed, all these amplitudes are joined in one.

The super-index $T$ has been employed to indicate transpose vector or matrix. The functions $J_{m}(\cdot)$ and $Y_{m}(\cdot)$ are, respectively, the Bessel functions of the first and second kind with order $m$. Non primate subscripts have been used for TM index and primate subscripts for TE index.

The values $k_{c m n}$ (cut-off wave number) and $\Gamma_{n}$ depend on the boundary conditions ( $\Gamma_{n}=0$ for the three-ports network). The propagation constant $\gamma_{m n}$ is related to cut-wave numbers as follows:

$$
k_{c m n}^{2}=k^{2}+\gamma_{m n}^{2}
$$

where $k$ is the free-space wave number $k=\omega \sqrt{\varepsilon \mu}$, and $\omega=2 \pi f$.

The definition of these parameters are applicable for TM and TE modes.

\section{Basis Functions of Circular Ports}

Chosen in a similar manner than [25]

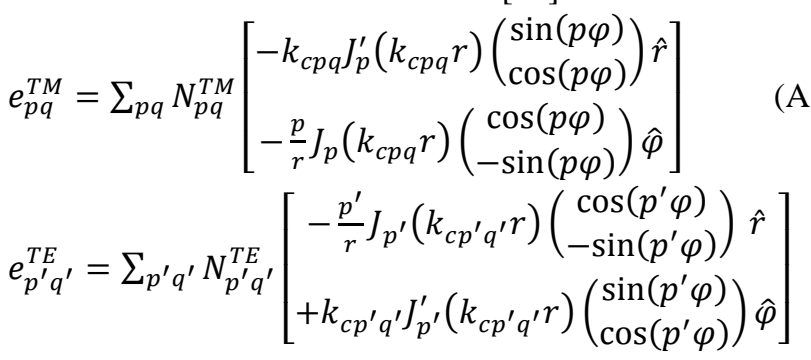

$h_{u v}^{T M}=\sum_{u v} N_{u v}^{T M}\left[\begin{array}{c}\frac{u}{r} J_{u}\left(k_{c u v} r\right)\left(\begin{array}{c}\cos (u \varphi) \\ -\sin (u \varphi)\end{array}\right) \hat{r} \\ -k_{c u v} J_{u}^{\prime}\left(k_{c u v} r\right)\left(\begin{array}{c}\sin (u \varphi) \\ \cos (u \varphi)\end{array}\right) \hat{\varphi}\end{array}\right]$

$h_{u^{\prime} v^{\prime}}^{T E}=\sum_{u^{\prime} v^{\prime}} N_{u^{\prime} v^{\prime}}^{T E}\left[\begin{array}{c}-k_{c u^{\prime} v^{\prime}} J_{u^{\prime}}^{\prime}\left(k_{c u^{\prime} v^{\prime}} r\right)\left(\begin{array}{c}\sin \left(u^{\prime} \varphi\right) \\ \cos \left(u^{\prime} \varphi\right)\end{array}\right) \hat{r} \\ -\frac{u^{\prime}}{r} J_{u^{\prime}}\left(k_{c u^{\prime} v^{\prime} r} r\right)\left(\begin{array}{c}\cos \left(u^{\prime} \varphi\right) \\ -\sin \left(u^{\prime} \varphi\right)\end{array}\right) \hat{\varphi}\end{array}\right]$

where, $k_{c i l}=\chi_{i l} / a$ and $k_{c i^{\prime} l^{\prime}}=\chi_{i^{\prime} l^{\prime}}^{\prime} / a$.

The constants $\chi_{i l}$ and $\chi_{i^{\prime} l^{\prime}}^{\prime}$ are the zeros of the first kind of Bessel function and its derivative respectively. $N_{m n}^{T M}$ and $N_{m n}^{T E}$ are the normalization factor of basis functions defined in [28]. Non primate subscripts have been used for TM index of basis functions and primate subscripts for TE index of basis functions. Subscripts $p$ and $q$ are employed for electric field series expansions; subscripts $u$ and $v$ are used for magnetic field series expansions.

\section{Basis Functions of Lateral Ports}

They are bi-dimensional Fourier series expansion.

$$
e_{p q}=\sum_{p q}\left(\begin{array}{c}
\sin (p \varphi) \sin \left(\frac{2 \pi q z}{h}\right) \\
\sin (p \varphi) \cos \left(\frac{2 \pi q z}{h}\right) \\
\cos (p \varphi) \sin \left(\frac{2 \pi q z}{h}\right) \\
\cos (p \varphi) \cos \left(\frac{2 \pi q z}{h}\right)
\end{array}\right)
$$




$$
h_{u v}=\sum_{u v}\left(\begin{array}{c}
\sin (u \varphi) \sin \left(\frac{2 \pi v z}{h}\right) \\
\sin (u \varphi) \cos \left(\frac{2 \pi v z}{h}\right) \\
\cos (u \varphi) \sin \left(\frac{2 \pi v z}{h}\right) \\
\cos (u \varphi) \cos \left(\frac{2 \pi v z}{h}\right)
\end{array}\right)
$$

\section{Integrals of Bessel Functions}

The analytical solution of integrals of Bessel functions has been solved using [30] and [31].

$$
\begin{gathered}
I_{N m n}^{T M}=\int_{0}^{a}\left[k_{c m n}^{2} J_{m}^{\prime}\left(k_{c m n} r\right)+\frac{m^{2}}{r^{2}} J_{m}^{2}\left(k_{c m n} r\right)\right] r d r \\
=\frac{\chi_{m n}^{2}}{2} J_{m}^{\prime 2}\left(\chi_{m n}\right) \\
I_{N m^{\prime} n^{\prime}}^{T E}=\int_{0}^{a}\left[k_{c m^{\prime} n^{\prime} J_{m^{\prime}}^{\prime 2}}^{\prime 2}\left(k^{\prime}{ }_{c m^{\prime} n^{\prime}} r\right)+\frac{{m^{\prime}}^{2}}{r^{2}} J_{m^{\prime}}^{2}\left(k_{b m^{\prime} n^{\prime}}^{\prime} r\right)\right] r d r \\
=\frac{\chi_{m^{\prime} n^{\prime}}^{\prime 2}}{2}\left(1-\frac{m^{\prime 2}}{\chi_{m^{\prime} n^{\prime}}^{\prime 2}}\right) J_{m}^{2}\left(\chi_{m^{\prime} n^{\prime}}^{\prime}\right)
\end{gathered}
$$$$
I_{12, u n v}^{T M T M}=\int_{0}^{a}\left[\begin{array}{c}
\frac{u^{2}}{r^{2}} J_{u}\left(k_{u n} r\right) J_{u}\left(\frac{\chi_{u v}}{a} r\right) \\
+k_{u n} \frac{\chi_{u v}}{a} J_{u}^{\prime}\left(k_{u n} r\right) J_{u}^{\prime}\left(\frac{\chi_{u v}}{a} r\right)
\end{array}\right] r d r
$$$$
=\frac{a^{2} \chi_{u v} k_{u n}^{2}}{a^{2} k_{u n}^{2}-\left(\chi_{u v}\right)^{2}} J_{u}\left(k_{u n} a\right) J_{u}^{\prime}\left(\chi_{u v}\right)
$$$$
I_{12, u n v}^{T E T E}=\int_{0}^{a}\left[\begin{array}{c}
\frac{u^{2}}{r^{2}} J_{u}\left(k_{u n} r\right) J_{u}\left(\frac{\chi_{u v}^{\prime}}{a} r\right) \\
+k_{u n} \frac{\chi_{u v}^{\prime}}{a} J_{u}^{\prime}\left(k_{u n} r\right) J_{u}^{\prime}\left(\frac{\chi_{u v}^{\prime}}{a} r\right)
\end{array}\right] r d r
$$$$
=\frac{a k_{u n} \chi_{u v}^{\prime}{ }^{2}}{\left(\chi_{u v}^{\prime}\right)^{2}-a^{2} k_{u n}^{2}} J_{u}^{\prime}\left(k_{u n} a\right) J_{u}\left(\chi_{u v}^{\prime}\right)
$$$$
\begin{gathered}
I_{12, u^{\prime} n v^{\prime}}^{T E T M}=\int_{0}^{a} u^{\prime}\left[\begin{array}{c}
J_{u^{\prime}}\left(\frac{\chi_{u^{\prime} v^{\prime}}^{\prime}}{a} r\right) J_{u^{\prime}}^{\prime}\left(k_{u^{\prime} n} r\right) k_{u^{\prime} n} \\
+\frac{\chi_{u^{\prime} v^{\prime}}^{\prime}}{a} J_{u^{\prime}}^{\prime}\left(\frac{\chi_{u^{\prime} v^{\prime}}^{\prime}}{a} r\right) J_{u^{\prime}}\left(k_{u^{\prime} n} r\right)
\end{array}\right] d r \\
=u^{\prime} J_{u^{\prime}}\left(\chi_{u^{\prime} v^{\prime}}^{\prime}\right) J_{u^{\prime}}\left(k_{u^{\prime} n} a\right)
\end{gathered}
$$

\section{Integrals of Trigonometric Functions}

$$
\begin{aligned}
& I_{n m}^{c h, c h}= \int_{0}^{h} \cosh \left(\frac{j n \pi}{h} z\right) \cosh \left(\frac{j m \pi}{h} z\right) d z \\
&=\frac{h}{2}(1+\operatorname{sinc}(n)) \delta_{m n} \\
& I_{n m}^{s h, s h}= \int_{0}^{h} \sinh \left(\frac{j n \pi}{h} z\right) \sinh \left(\frac{j m \pi}{h} z\right) d z \\
&= \frac{-h}{2}(1-\operatorname{sinc}(n)) \delta_{m n} \\
& I_{n m}^{c h, s}= \int_{0}^{h} \cosh \left(\frac{j n \pi}{h} z\right) \sin \left(\frac{2 \pi m}{h} z\right) d z \\
&=-h m \pi \operatorname{sinc}\left(\frac{n}{2}+m\right) \operatorname{sinc}\left(\frac{n}{2}-m\right) \\
& I_{n m}^{c h, c}=\int_{0}^{h} \cosh \left(\frac{j n \pi}{h} z\right) \cos \left(\frac{2 \pi m}{h} z\right) d z \\
&=\frac{h}{2}(1+\sin c(n)) \delta(n-2 m)
\end{aligned}
$$

$$
\begin{gathered}
I_{n m}^{s h, s}=\int_{0}^{h} \sinh \left(\frac{j n \pi}{h} z\right) \sin \left(\frac{2 \pi m}{h} z\right) d z \\
=\frac{j h}{2}(1-\operatorname{sinc}(n)) \delta(n-2 m) \\
I_{n m}^{s h, c}=\int_{0}^{h} \sinh \left(\frac{j n \pi}{h} z\right) \cos \left(\frac{2 \pi m}{h} z\right) d z \\
=j \frac{n}{2} \pi h \operatorname{sinc}\left(\frac{n}{2}+m\right) \operatorname{sinc}\left(\frac{n}{2}-m\right) \\
I_{21, v^{\prime} n^{\prime}}^{s, s h}=\int_{0}^{h} \sinh \left(\gamma_{n^{\prime}} z\right) \sin \left(\frac{2 \pi v^{\prime} z}{h}\right) d z \\
=-\frac{2 \pi h v^{\prime} \sinh \left(\gamma_{n^{\prime}} h\right)}{\gamma_{n^{\prime}}^{2} h^{2}+\left(2 \pi v^{\prime}\right)^{2}} \\
I_{21, v^{\prime} n^{\prime}}^{c, s h}=\int_{0}^{h} \sinh \left(\gamma_{n^{\prime}} z\right) \cos \left(\frac{2 \pi v^{\prime} z}{h}\right) d z \\
=\frac{\gamma_{n^{\prime}} h^{2}\left(\cosh \left(\gamma_{n^{\prime}} h\right)-1\right)}{\left(\gamma_{n^{\prime}}\right)^{2}+\left(2 \pi v^{\prime}\right)^{2}} \\
I_{21, v n}^{s, c h}=\int_{0}^{h} \cosh \left(\gamma_{n} z\right) \sin \left(\frac{2 \pi v z}{h}\right) d z \\
=-\frac{2 \pi h v\left(\cosh \left(\gamma_{n} h\right)-1\right)}{\gamma_{n}^{2} h^{2}+(2 \pi v)^{2}} \\
I_{21, v n}^{c, c h}=\int_{0}^{h} \cosh \left(\gamma_{n} z\right) \cos \left(\frac{2 \pi v z}{h}\right) d z \\
=\frac{\gamma_{n} h^{2} \sinh \left(\gamma_{n} h\right)}{\left(\gamma_{n} h\right)^{2}+(2 \pi v)^{2}}
\end{gathered}
$$

\section{REFERENCES}

[1] P. I. Dankov and B. N. Hadjistamov, "Characterization of microwave substrates with split-cylinder and split-coaxial-cylinder resonators," 2007 European Microwave Conference, Munich, 2007, pp. 933-936.

[2] M. M. Taheri and D. Mirshekar-Syahkal, "Accurate determination of modes in dielectric-loaded cylindrical cavities using a one-dimensional finite element method," IEEE Trans. Microw. Theory Techn., vol. 37, no. 10, pp. 1536-1541, Oct 1989.

[3] M. D. Janezic and J. Baker-Jarvis, "Full-wave analysis of a splitcylinder resonator for nondestructive permittivity measurements," IEEE Trans. Microw. Theory Techn, vol. 47, no. 10, pp. 2014-2020, Oct 1999.

[4] S. Omar and D. Jiao, "A New Volume Integral Formulation for Broadband 3-D Circuit Extraction in Inhomogeneous Materials With and Without External Electromagnetic Fields," IEEE Trans. Microw. Theory Techn., vol. 61, no. 12, pp. 4302-4312, Dec. 2013.

[5] Giuseppe Conciauro, Marco Guglielmi, and Roberto Sorrentino, Advanced Modal Analysis.

[6] R. Sorrentino, F. Alessandri, M. Mongiardo, and G. Schiavon, "Efficient Computer-Aided Design of Wideband Stepped Waveguide Phase Shifters,"1990 20th European Microwave Conference, Budapest, Hungary, 1990, pp. 463-468.

[7] R. Sorrentino, F. Alessandri, M. Mongiardo, G. Avitabile, and L. Roselli, "Full-wave modeling of via hole grounds in microstrip by threedimensional mode matching technique," in IEEE Transactions on Microwave Theory and Techniques, vol. 40, no. 12, pp. 2228-2234, Dec 1992.

[8] F. Alessandri, M. Barba, M. Mongiardo, and R. Sorrentino, "Rigorous and efficient analysis of hybrid T-junctions," 1993 IEEE MTT-S International Microwave Symposium Digest, Atlanta, GA, USA, 1993, pp. $1447-1450$ vol.3.

[9] S. Moretti, F. Alessandri, and R. Sorrentino, "Field theory design of a nove circular waveguide dual mode filter," 1995 25th European Microwave Conference, Bologna, Italy, 1995, pp. 779-783.

[10] F. L. Penaranda-Foix and J. M. Catala-Civera, "Circuital analysis of cylindrical structures applied to the electromagnetic resolution of resonant cavities," Chapter 7 in Passive Microwave Components and Antennas, Vukovar, Croatia: InTech, April 2010.

[11] F. L. Penaranda-Foix, J. M. Catala-Civera, A. J. Canos-Marin, and B. Garcia-Banos, "Circuital analysis of a coaxial re-entrant cavity for performing dielectric measurement," 2009 IEEE MTT-S International Microwave Symposium Digest, Boston, MA, 2009, pp. 1309-1312.

[12] F. L. Penaranda-Foix, M. D. Janezic, J. M. Catala-Civera, and A. J. Canos, "Full-Wave Analysis of Dielectric-Loaded Cylindrical Waveguides and Cavities Using a New Four-Port Ring Network," IEEE 
Trans. Microw. Theory Techn., vol. 60, no. 9, pp. 2730-2740, Sept. 2012.

[13] F. L. Penaranda-Foix, P. J. Plaza-Gonzalez, B. Garcia-Banos, and D. Polo-Nieves, "A nondestructive method of measuring the dielectric and magnetic properties of laminate materials in open cavities," 2004 IEEE MTT-S International Microwave Symposium Digest, 2004, pp. 18211823 vol.3.

[14] J. M. Catalá-Civera, A. J. Canós, P. Plaza-González, J. D. Gutiérrez, B. García-Baños, and F. L. Peñaranda-Foix, "Dynamic Measurement of Dielectric Properties of Materials at High Temperature During Microwave Heating in a Dual Mode Cylindrical Cavity," IEEE Trans. Microw. Theory Techn., vol. 63, no. 9, pp. 2905-2914, Sept. 2015.

[15] K. A. Zaki and A. E. Atia, "Modes in Dielectric-Loaded Waveguides and Resonators," IEEE Trans. Microw. Theory Techn., vol. 31, no. 12, pp. 1039-1045, Dec. 1983.

[16] Y. Rong and K. A. Zaki, "Full-wave analysis of coupling between cylindrical combline resonators," IEEE Trans. Microw. Theory Techn., vol. 47, no. 9, pp. 1721-1729, Sep 1999.

[17] M. Polewski, R. Lech, and J. Mazur, "Rigorous modal analysis of structures containing inhomogeneous dielectric cylinders," IEEE Trans. Microw. Theory Techn., vol. 52, no. 5, pp. 1508-1516, May 2004.

[18] A. H. Sklavounos and N. S. Barker, "Liquid-Permittivity Measurements Using a Rigorously Modeled Overmoded Cavity Resonator," IEEE Trans. Microw. Theory Techn., vol. 62, no. 6, pp. 1363-1372, June 2014

[19] S. Zinal and U. Arz, "An extended mode-matching model for improved relative permittivity measurements using a split cylinder resonator," Adv. Radio Sci., vol. 12, Nov. 2014, pp. 267-272.

[20] M. Janezic, E. F. Kuester, and J. Baker-Jarvis, "Broadband complex permittivity measurements of dielectric substrates using a split-cylinder resonator," IEEE MTT-S International Microwave Symposium, Vol. 3, July 2004, pp. 1817-1820.

[21] U. Arz, J. Leinhos and M. D. Janezic, "Broadband Dielectric Material Characterization: A Comparison of On-Wafer and Split-Cylinder Resonator Measurements," 2008 38th European Microwave Conference, Amsterdam, 2008, pp. 913-916.

[22] Xiangyi Fang, D. Linton, C. Walker, and B. Collins, "A tunable split resonator method for nondestructive permittivity characterization," IEEE Trans. Microw. Theory Techn., vol. 53, no. 6, pp. 1473-1478, Dec. 2004

[23] D. Marqués-Villarroya, F. Peñaranda-Foix, B. García-Baños, J. M. Catalá-Civera and J. D. Gutiérrez-Cano, "Full-wave circuit analysis of a split-cylinder cavity," 2016 IEEE MTT-S International Microwave Symposium (IMS), San Francisco, CA, 2016, pp. 1-4.

[24] R. E. Collin, Field Theory of Guided Waves. New York: McGraw-Hill, 1960.

[25] J. D. Wade and R. H. Macphie, "Scattering at Circular-to-Rectangular Waveguide Junctions," IEEE Trans. Microw. Theory Techn., vol. 34, no. 11, pp. 1085-1091, Nov 1986.

[26] M. D. Janezic, U. Arz, S. Begley and P. Bartley, "Improved permittivity measurement of dielectric substrates by use of the $\mathrm{TE}_{111}$ mode of a splitcylinder cavity," 2009 73rd ARFTG Microwave Measurement Conference, Boston, MA, 2009, pp. 1-3.

[27] Howard E. Bussey, Derek Morris, and E. B. Zal'tsman, "International comparison of complex permittivity measurement at $9 \mathrm{GHz}$," IEEE Transactions on Instrumentation and Measurement, vol. IM-23, no. 3, pp. 235- 239, Sept. 1974.

[28] R. E. Collin, Foundations for Microwave Engineering. New York: McGraw-Hill, 1966

[29] C. A. Balanis, Advanced Engineering Electromagnetics. John Wiley \& Sons, 1989

[30] M. Abramowitz and I.A. Stegun, Handbook of Mathematical Functions. Dover. New York, 1965.

[31] E. B. Manring and J. Asmussen, "Useful Bessel function identities and integrals," IEEE Trans. Microw. Theory Techn., vol. 41, no. 8, pp. 1468-1471, Aug 1993.

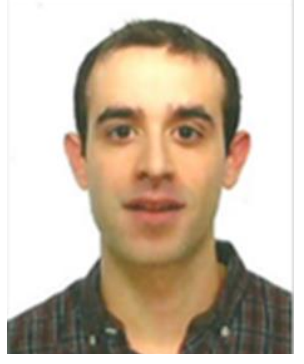

David Marqués-Villarroya was born in Benicarló, Spain, 1991. He received the M.S. degree in electrical engineering from the Universitat Politècnica de València, Spain, in 2014, and he is currently working toward the $\mathrm{Ph} . \mathrm{D}$. degree at the same university.

In 2014, he joined the Institute for the Applications of Information Technology and Advanced Communications (ITACA), Universitat Politècnica de València, with a Research Fellowship of the university itself. In 2015, he was awarded by the Spanish College of Telecommunication Engineers for his Final Degree Project.

His research interests include full-wave analysis, electromagnetic characterization of materials, computational electromagnetics and numerical methods.

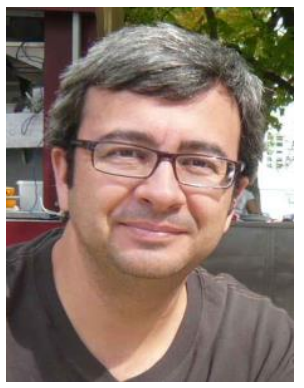

Felipe L. Peñaranda-Foix (M'92-SM'00) was born in Benicarló (Spain) in 1967. He received the M.S. degree in electrical engineering from Universidad Politécnica de Madrid, Madrid, Spain, in 1992, and the Ph.D. degree in electrical engineering from Universidad Politécnica de Valencia (UPV), Valencia, Spain, in 2001.

In 1992, he joined the Departamento de Comunicaciones, UPV, where he is currently a Senior Lecturer. His current research interests include electromagnetic scattering, microwave circuits and cavities, sensors and microwave heating applications.

He has co-authored about 40 papers in referred journals and conference proceedings and more than 40 engineering reports for companies.

Dr. Peñaranda-Foix is IEEE and AMPERE member and reviewer of several international Journals.

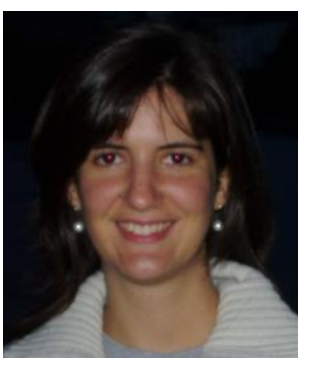

Beatriz García-Baños was born in Madrid (Spain) in 1979. She recevied the B.S., M.S. and Ph.D. degrees in Communications from the Universidad Politécnica de Valencia, Valencia, Spain in 2003, 2005 and 2008, respectively. She was a research assistant with the Universidad Politécnica de Valencia from 2003 to 2008. In 2008 she joined the Microwaves Industrial Applications Division (DIMAS) at the Institute for the Applications of Advanced Information and Communication Technologies (ITACA) where she is specialized in developing microwave equipment for dielectric characterization, materials and process monitoring and heating processes. She has authored or coauthored more than 30 papers and conference proceedings, and she is the author of the book: Study and optimization of microwave sensors for characterization and monitoring of materials in industrial processes (Madrid, Spain: ProQuest Dissertations \& Thesis, 2009). She holds one patent. Her research interests include microwave sensors and systems for materials characterization, microwave monitoring of industrial processes, and microwave heating devices.

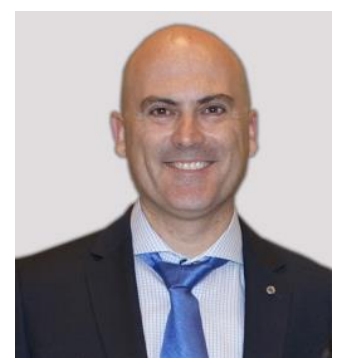

Jose M. Catalá-Civera was born in Valencia (Spain) in February 1969. He received the Dipl. Ing. and Ph.D. degrees from the Universitat Politècnica de València, Spain, in 1993 and 2000, respectively. Since 1996, he has been with the Communications Department, Universidad Politécnica de Valencia, where he received the Readership in 2000 becoming full professor in 2011. Currently he is head of the Microwave Applications Research Division of the Institute ITACA at the Universidad Politécnica de Valencia. His research interests encompass the design and application of microwave theory and applications, the use of microwaves for electromagnetic heating, microwave cavities and resonators, measurement of dielectric and magnetic properties of materials and development of microwave sensors for non-destructive testing. He has co- 
authored about 100 papers in referred journals and conference proceedings, more than 50 engineering reports for companies and he holds 13 patents. Dr. Catala-Civera is IEEE Member, IMPI Member, he is reviewer of several international Journals and is currently Board Member of the Association of Microwave Power in Europe for Research and Education (AMPERE), a European-based organization devoted to the promotion of RF and microwave energy.

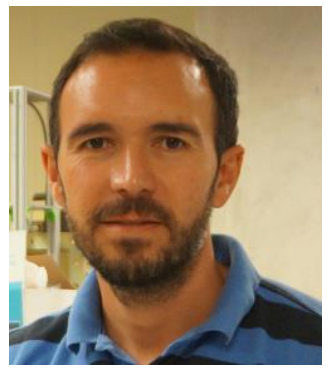

José D. Gutiérrez-Cano was born in Molinicos (Albacete), Spain, in 1984. He received the Dipl.Eng. in electrical engineering from the Universitat Politècnica de València (UPV), Valencia, Spain, in 2008. In 2008 , he joined the microwave division in the Institute for the Information and Communication Technologies (ITACA), UPV, as a Research and Development Engineer and as a Laboratory Technician.

His current research interests include microwave measurement techniques, devices for the electromagnetic characterization of materials and industrial microwave processes. 